\title{
EFFECT OF STYRENE MALEIC ANHYDRIDE ON PHYSICAL AND MECHANICAL PROPERTIES OF RECYCLED POLYSTYRENE WOOD FLOUR COMPOSITES
}

Matheus Poletto ${ }^{1, \AA}$

\begin{abstract}
In this work, the influence of three types of styrene maleic anhydride (SMA) oligomers on the adhesion of polystyrene wood plastic composites (WPC) was investigated. The composites were processed on a twin-screw co-rotating extruder below $200^{\circ} \mathrm{C}$ using $20 \mathrm{wt} \%$ of wood flour. The styrene maleic anhydride with different content of maleic anhydride groups, $30 \%, 25 \%$ and $20 \%(\mathrm{w} / \mathrm{w})$ and levels of 1,2 and $4 \%$ of coupling agents (styrene maleic anhydride 2000, styrene maleic anhydride 3000 and styrene maleic anhydride EF40) in the composite formulations were tested. Mechanical, physical and morphologic properties were evaluated. The styrene maleic anhydride improves the compatibility of hydrophilic wood flour with hydrophobic polystyrene matrix. It has been observed that the addition of styrene maleic anhydride increased the wood plastic composites mechanical properties with the incorporation of $2 \% \mathrm{wt}$ of styrene maleic anhydride 2000 . The mechanical properties showed to be dependent on content of maleic anhydride in the coupling agent. Treated and non-treated wood plastic composites showed similar density values, but the void content was reduced for treated composites. Scanning electron microscopy revel the better adhesion between polymer and matrix when coupling agent were used.
\end{abstract}

Keywords: Coupling agent, injection moulding, mechanical properties, Pinus elliottii, polystyrene, wood plastic composites.

\section{INTRODUCTION}

The utilization of biomass for processing novel composites has attracted growing interest because of this eco-friendly and renewable nature (Sliwa et al. 2012, Nafchi et al. 2015). Materials reinforced with wood flour and others natural fibres increased considerably in recent years (Ornaghi Jr. et al. 2014). Wood flour is easily available, light and cheap, and it can be added to commodity matrices in large quantities thus offering economically advantageous solutions (Poletto et al. 2014, Khonsari et al. 2015). The main application areas of wood plastic composites (WPC) are the automotive and building industries (Nafchi et al. 2015) in which they are used in structural applications as door panels, decking, furniture, window parts, etc. However, in wood industry a large amount of wood waste is generated at different stages of the wood processing and such waste is mainly destined for landfill. Industrial region of Caxias do Sul, situated in northeast region of Rio Grande do Sul/Brazil, generates higher quantities of industrial and urban wastes. The furniture industry generates approximately 5500 $\mathrm{m}^{3} /$ month of Pinus elliottii sawdust. On the other hand, plastic waste is one the major components of global municipal solid waste and, as such, it presents a promising raw materials source for WPC, especially because of large volume (Cui et al. 2008). Expanded polystyrene (EPS) is commonly used

${ }^{1}$ Centro de Ciências Exatas, da Natureza e de Tecnologia (CENT), Universidade de Caxias do Sul (UCS), Bento Gonçalves, Rio Grande do Sul, Brazil.

"Corresponding author: mpolett1@ucs.br

Received: 21.09.2015 Accepted: 05.06.2016 
for packing materials, and after use EPS usually ends up in landfills or is incinerated. The estimate for generation of waste EPS in Caxias do Sul is about $1240 \mathrm{~m}^{3} / \mathrm{month}$. The EPS wastes are deposited in the city landfill reducing drastically the area of the landfill. Thus, increased use of recycled plastics offers the prospect of lessening waste disposals and reducing the products costs (Adhikary et al. 2008). Hence, the development of new value added WPC products using wood waste and recycled plastic is assuming greater importance in environmental conservation.

One of the main disadvantages of WPC is the low compatibility between the hydrophilic wood filler and hydrophobic polymer matrix (El-Sabbagh 2014, Kim et al. 2007). Thus, two ways of improvement of the interface properties are generally used surface treatment of the reinforced fibres in order to increase their compatibility whit the surrounding polymer, or modification of the matrix (El-Sabbagh 2014). The introduction of functional groups inside the polymer chains of the matrix aims to create chemical or physical interactions with the reinforcing fibres, and is a solution which leads to excellent results in practice. The maleic anhydride introduce by radical copolymerization in styrene constitutes one of the most efficient modifications agents used to functionalize the styrenic polymers (Devaux et al. 2002). Then, high molecular weight copolymers based on polystyrene and maleic anhydride may act as coupling agents in polystyrene composites reinforced by natural fibers. Sommerhuber et al. (2016) developed WPC based on recycled polystyrene reinforced with wood flour and evaluated the effect of $3 \%$ of SMA on the composite mechanical properties. The authors observed a significantly improve in tensile and flexural strength properties attributed to the better adhesion between wood and polymer matrix caused by SMA. Poletto et al. (2015) used 2\% of SMA as coupling agent in polystyrene cellulose fiber composites. The addition of coupling agent substantially improves the mechanical and dynamic mechanical properties evaluated.

Therefore, the main goal of this study was to investigate the effect of three different styrene-comaleic anhydride (SMA) oligomers in the adhesion of polystyrene composites reinforced with wood flour wastes. The influence of the maleic anhydride concentration in the copolymers on the mechanical, physical and morphologic properties of the WPC was evaluated.

\section{MATERIALS AND METHODS}

\section{Materials}

EPS wastes were obtained from a sorting unit called Associação de Recicladores Serrano, Caxias do Sul, Brazil, and it had a melt flow index (MFI) of $20 \mathrm{~g} / 10 \mathrm{~min}\left(200^{\circ} \mathrm{C} / 5 \mathrm{~kg}\right)$. Wood flour of Pinus elliottii (PIE) was obtained from Madarco Co., Caxias do Sul, Brazil. The three types of SMA used as a coupling agent were supplied by Sartomer Company, Exton/USA. SMA 2000 contains 30\% w/w of maleic anhydride groups and weight average molecular weight $\left(\mathrm{M}_{\mathrm{w}}\right)$ of $7500 \mathrm{~g} / \mathrm{mol}$, SMA 3000 whit $25 \% \mathrm{w} / \mathrm{w}$ of maleic anhydride groups and $\mathrm{M}_{\mathrm{w}}$ of $9500 \mathrm{~g} / \mathrm{mol}$ and SMA EF40 contains $20 \% \mathrm{w} / \mathrm{w}$ of maleic anhydride groups and $\mathrm{M}_{\mathrm{w}}$ of $10500 \mathrm{~g} / \mathrm{mol}$. The chemical structures of SMA used were showed in Figure 1. SMA was incorporated at 1, 2 and 4\% in weight of coupling agents (SMA 2000, SMA 3000 and SMA EF40) in the WPC.

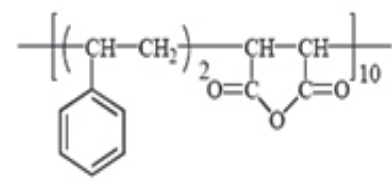

(a)

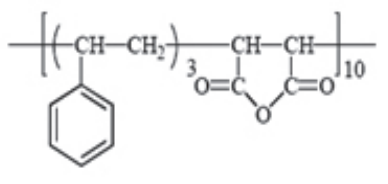

(b)

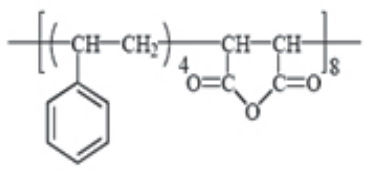

(c)

Figure 1. Chemical structure of SMA used as coupling agents, SMA 2000 ,(a), SMA 3000, (b), and SMA EF40, (c). 


\section{Composite preparation}

The wood flour was dried in an oven at $105^{\circ} \mathrm{C}$ for $24 \mathrm{~h}$. WPC samples with $20 \mathrm{w} / \mathrm{w} \%$ of wood flour and with and without 1,2 , and $4 \mathrm{wt} \%$ of poly(styrene-co-maleic anhydride) oligomer were processed in a co-rotating twin-screw extruder COR-20-32-LAB MH Equipment-Brazil at $200 \mathrm{rpm}$, with L/D ratio of 32 into pellets. The nine barrel temperature zones were controlled at between $160^{\circ} \mathrm{C}$ and $190^{\circ} \mathrm{C}$. Specimens for mechanical and physical tests were injection molded in a HIMACO LH 150-80 equipment at a barrel temperature of $180^{\circ} \mathrm{C}$ and mold temperature of $40 \pm 2^{\circ} \mathrm{C}$, with screw speed of 100 $\mathrm{rpm}$ and pressure of 650 bar.

\section{Wood flour particle size distribution}

The wood flour particle size distribution was determined based on ASTM D1921 - Method A. A sample of $50 \mathrm{~g}$ of wood flour previously dried was placed on a mechanical sieving device with selected sieves $(28,35,48,65,100,150,200,325$ mesh). The measurements were carried out in triplicate.

\section{Mechanical properties}

Flexural tests were performed according to ASTM D790 at a cross-head speed of 1,5 mm.min ${ }^{-1}$ using EMIC DL 3000 testing machine. Izod impact strength was measured with a CEAST Resil 25 pendulum using unnotched specimens according to ASTM D256. Each test value was obtained as the average of at least five independent measurements.

\section{Physical properties}

Density for polystyrene and WPC were determined according ASTM D792. Each density value was obtained as the average of at least three independent measurements.

\section{Water absorption test}

For water absorption, rectangular specimens having dimensions of $100 \mathrm{~mm} \times 13 \mathrm{~mm}$ x 3,5 $\mathrm{mm}$ were used. The specimens were dried in an oven at $80^{\circ} \mathrm{C}$ for $24 \mathrm{~h}$, cooled in a desiccators using silica gel and immediately weighed. The water absorption test were carried out in triplicate immersing the specimens for $2 \mathrm{~h}, 24 \mathrm{~h}$ and $48 \mathrm{~h}$ in distilled water at $23^{\circ} \mathrm{C}$. After immersion, the excess water on the surface of the specimens was wiped up using a piece of soft cloth and the final weights of the specimens were then taken. From the difference of weights of the specimens percentage of water absorption was calculated.

\section{Morphological study}

Studies on the morphology of wood flour and composites samples were carried out using a SHIMADZU Superscan SS-550, scanning electron microscope (SEM). The cryo fracture surface specimens were sputter-coated with gold before the analysis in order to eliminate electron charging.

\section{Statistical analysis}

The statistical analysis of variance for composite mechanical properties has been carried out using commercial software (EXCEL). A one-way analysis of variance and t-tests were used to evaluate the statistical difference among groups. Values of $p<0,05$ were considered significant. 


\section{RESULTS AND DISCUSSIONS}

\section{Wood flour characterization}

Fiber size and shape are among the most important factors related to composite materials (Bledzki et al. 2010). The effective surface area, which influence on mechanical properties inversely depends on particle size and shape (Bledzki et al. 2010, Poletto et al. 2012). Figure 2 shows the particle size and shape of the wood flour used in the WPC formulations. The particle size distribution is showed in the inset of Figure 2(a). It was observed that approximately $80 \%$ of all fibers were distributed in the range of $40-150 \mu \mathrm{m}$, although the distribution varied. Short and tiny fibers are preferable for the development of WPC formulations, since these provide a higher specific surface area and greater surface area of contact with the polymer matrix which usually produces better fiber-matrix adhesion when the coupling agent is used and an increase in the mechanical properties are normally observed (Gallagher et al. 2013).

The fiber surface morphology plays a vital role in the case of composite materials. The external surface features of the wood flour can be observed in Figure 2(b). The wood fiber surface is rough, which can provide mechanical anchoring to the polymer matrix and thus lead to improved mechanical properties compared to particles with smooth surfaces.
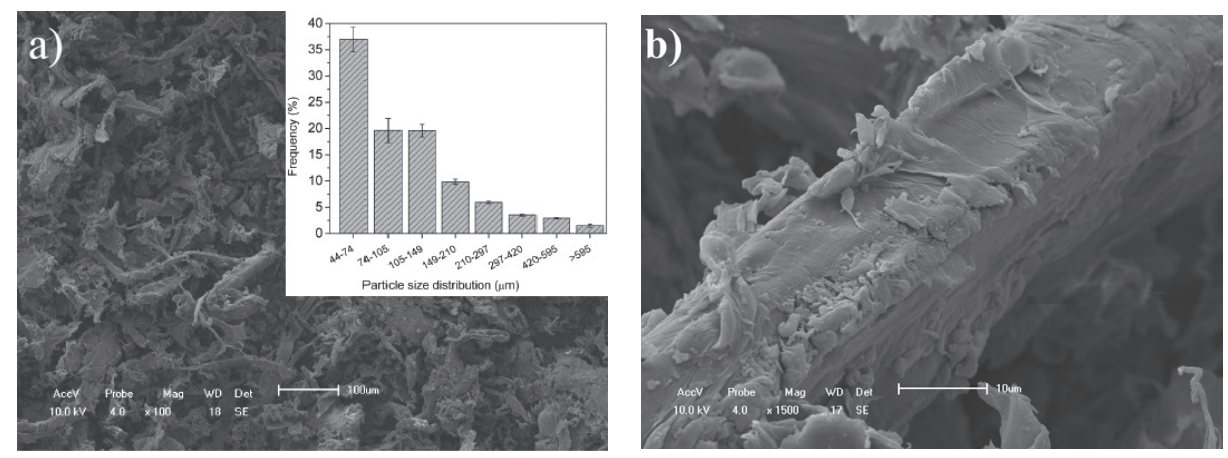

Figure 2. (a)SEM micrograph with magnification of 100x of wood flour and a (b) SEM micrograph detail (magnification 1500x) of wood fiber surface morphology.

\section{Mechanical Properties}

Table 1 showed the flexural strength and flexural modulus for the WPC with different SMA oligomers studied. The quantities of styrene-co-maleic anhydride necessary to obtain a maximum resistance in flexural strength are about $1-2 \%$. The maximum value was obtained with $2 \%$ of the SMA 2000 , as can be observed in Table 1 . This coupling agent contains $30 \%$ of maleic anhydride groups, more content than others, and weight average molecular weight of $7500 \mathrm{~g} / \mathrm{mol}$, the lowest weight average molecular weight. The fact that the strong maleic anhydride concentration in oligomers tends to increase the probability of these functional groups being presents near to the wood flour. In addition, the low molecular weight of these SMA oligomers gives them sufficient fluidity in the molten state and thus supports their migration towards the fibre surface (Devaux et al. 2002, Bledzki et al. 2005). This phenomenon causes a preferential localization of SMA to the fibre-matrix interface, and thus increases the possibilities of interaction with wood flour (Gallagher et al. 2013). The statistical analysis revel that no significant differences between flexural strength values were obtained using $1 \%$ or $2 \%$ of coupling agent for the three coupling agents tested. However, SMA 2000 presented better results than the others two oligomers used. It can be also concluded from the statistical analysis that uncompatibilized WPC had lower flexural strength than composites treated with SMA, which may be associated with the better compatibility between matrix and filler promoted by the coupling agent. The usage of SMA 3000 and 
SMA EF40 decreased the composites flexural strength when compared with composites treated with SMA 2000. This might be explained based on the lower maleic anhydride content in SMA 3000 and SMA EF40 when compared with SMA 2000, resulting in lower adhesion between matrix and filler. The composites treated with SMA 2000 presented higher flexural modulus when compared with the others oligomers used. In addition, the flexural modulus followed the same behavior that the flexural strength and composites with $2 \mathrm{wt} \%$ of SMA 2000 showed the highest modulus values. Adding $1 \%$ of SMA 2000 did not affect the flexural modulus when compared with the composite without coupling agent and further increase in the coupling agent content (2wt\% SMA 2000) did not alter the flexural modulus values appreciably. SMA 3000 promotes a significantly decrease in flexural modulus when compared with untreated composite and treated with SMA 2000. This behavior is probably associated with the lower maleic anhydride content in SMA 3000.

Impact strength decrease with the addition of $2 \mathrm{wt} \%$ of SMA 2000 , as can be seen in Table 1 , probably because occur an increase in the formation of entanglement between the fiber and matrix (Nygård et al. 2008). Furthermore, the sufficient number of maleic anhydride groups in SMA 2000 attached onto the PS chains causes strong interfacial interaction, probably due the formation of chemical bonds between these groups and hydroxyl groups of wood flour (Naghmouchi et al. 2015). Statistical analysis revel that no significant differences between impact strength values were observed with addition of different levels of SMA 2000 or SMA 3000. Composites treated with SMA EF 40 showed the highest impact strength values. This result may be attribute to the lower content of maleic anhydride groups in this coupling agent, with reduces the formation of entanglement between the fiber and matrix, which can promote a better energy absorption by the polymer matrix during the impact test.

Table 1. Effect of coupling agent type and percent on the mechanical properties.

\begin{tabular}{|c|c|c|c|c|c|c|c|c|c|c|}
\hline \multirow{3}{*}{$\begin{array}{c}\text { Mechanical } \\
\text { properties } \\
\text { evaluated }\end{array}$} & \multicolumn{10}{|c|}{ Coupling agent } \\
\hline & & \multicolumn{3}{|c|}{ SMA 2000} & \multicolumn{3}{|c|}{ SMA 3000} & \multicolumn{3}{|c|}{ SMA EF40 } \\
\hline & 0 & 1 & 2 & 4 & 1 & 2 & 4 & 1 & 2 & 4 \\
\hline $\begin{array}{c}\text { Flexural } \\
\text { strength } \\
(\mathrm{MPa})\end{array}$ & $\begin{array}{l}54,94^{\mathrm{d}} \\
(2,73)\end{array}$ & $\begin{array}{l}64,81^{\mathrm{a}} \\
(1,73)\end{array}$ & $\begin{array}{l}66,69^{\mathrm{a}} \\
(2,91)\end{array}$ & $\begin{array}{l}44,18^{b} \\
(2,85)\end{array}$ & $\begin{array}{c}56,51^{\mathrm{d}, \mathrm{f}, \mathrm{g}} \\
(2,26)\end{array}$ & $\begin{array}{c}59,22^{\mathrm{d}, \mathrm{f}} \\
(1,63)\end{array}$ & $\begin{array}{l}42,52^{\mathrm{e}} \\
(1,92)\end{array}$ & $\begin{array}{c}58,13^{\mathrm{d}, \mathrm{g}, \mathrm{h}} \\
(3,35)\end{array}$ & $\begin{array}{c}59,06^{\mathrm{d}, \mathrm{h}} \\
(0,96)\end{array}$ & $\begin{array}{l}44,98^{c} \\
(3,91)\end{array}$ \\
\hline $\begin{array}{l}\text { Flexural } \\
\text { modulus } \\
(\mathrm{MPa})\end{array}$ & $\begin{array}{c}4564^{a} \\
(72)\end{array}$ & $\begin{array}{c}4427^{\mathrm{a}, \mathrm{d}} \\
(140)\end{array}$ & $\begin{array}{c}4701^{a, b} \\
(143)\end{array}$ & $\begin{array}{l}4850^{\mathrm{b}} \\
(122)\end{array}$ & $\begin{array}{c}4213^{\mathrm{c}, \mathrm{d}, \mathrm{e}} \\
(188)\end{array}$ & $\begin{array}{c}4209^{c} \\
(88)\end{array}$ & $\begin{array}{l}4380^{c} \\
(138)\end{array}$ & $\begin{array}{c}4194^{\mathrm{e}} \\
(73)\end{array}$ & $\begin{array}{c}4661^{\mathrm{a}, \mathrm{f}} \\
(284)\end{array}$ & $\begin{array}{l}4756^{\mathrm{f}} \\
(148)\end{array}$ \\
\hline $\begin{array}{c}\text { Impact } \\
\text { Strength } \\
(\mathrm{J} / \mathrm{m})\end{array}$ & $\begin{array}{l}95,98^{a} \\
(1,62)\end{array}$ & $\begin{array}{l}97,20^{\mathrm{a}} \\
(3,92)\end{array}$ & $\begin{array}{l}93,23^{\mathrm{a}} \\
(5,00)\end{array}$ & $\begin{array}{l}92,82^{\mathrm{a}} \\
(4,58)\end{array}$ & $\begin{array}{l}92,62^{\mathrm{a}} \\
(4,75)\end{array}$ & $\begin{array}{l}97,24^{a} \\
(2,39)\end{array}$ & $\begin{array}{l}91,22^{\mathrm{b}} \\
(2,74)\end{array}$ & $\begin{array}{l}102,0^{\mathrm{c}} \\
(1,04)\end{array}$ & $\begin{array}{c}107,43^{\mathrm{d}} \\
(3,30)\end{array}$ & $\begin{array}{l}98,51^{\mathrm{a}} \\
(2,51)\end{array}$ \\
\hline
\end{tabular}

Values for standard deviation are given in parentheses.

Results with the same superscript letter in their respective line are significantly the same.

The addition of SMA 2000 increased the flexural strength and flexural modulus, but drastically reduced the impact strength. This behavior is more evident when $1-2 \mathrm{wt} \%$ of SMA 2000 was used. The interactions formed between polymer matrix and wood flour when SMA 2000 was used probably reduces the molecular mobility of matrix which reduces the energy absorption on impact, causing a reduction in composite impact strength. However, based on the flexural tests composites with $2 \mathrm{wt} \%$ of SMA 2000 showed the better mechanical performance when compared with the others composites studied.

\section{Density}

Mechanical properties of polymer composites are well known to be affected strongly by internal defects such as voids (Takagi et al. 2008, Poletto et al. 2011). Consequently, the density and void content usually serve as good indicators for composite strength (Borja et al. 2006, Takagi et al. 2008). 
The measured density values were compared to the calculated ones on the basis of the following relationship, based on the rule of mixtures:

$$
\rho_{c}=\rho_{E P S r} W_{E P S r}+\rho_{w f} W_{w f} \quad \text { (Equation 1) }
$$

where $\rho_{c}$ is the calculated density of the composite material $\left(\mathrm{g} / \mathrm{cm}^{3}\right), \rho_{E P S r}$ is the density of EPS-r $\left(1,07 \mathrm{~g} / \mathrm{cm}^{3}\right)^{c}, \rho_{w f}$ is the density of the wood flour $\left(1,41 \mathrm{~g} / \mathrm{cm}^{3}\right), W_{E P S r}$ is the weight fraction of EPS-r (wt $\%)$, and $W_{w f}$ is the weight fraction of the wood flour ( $\left.\mathrm{wt} \%\right)$.

Void content was obtained according to:

$$
V=100\left(\frac{\rho_{c}-\rho_{m}}{\rho_{c}}\right) \quad \text { (Equation 2) }
$$

where $V$ is the void content $(\%)$, and $\rho_{m}$ is the measured density of the composite material $\left(\mathrm{g} / \mathrm{cm}^{3}\right)$.

The experimental results for polymer matrix, composites with and without $2 \mathrm{wt} \%$ of SMA 2000 and calculated density value were shown in Figure 3(a). The composite without coupling agent showed slightly lower density than composite with SMA. However, the experimental results were lower than the calculated values.
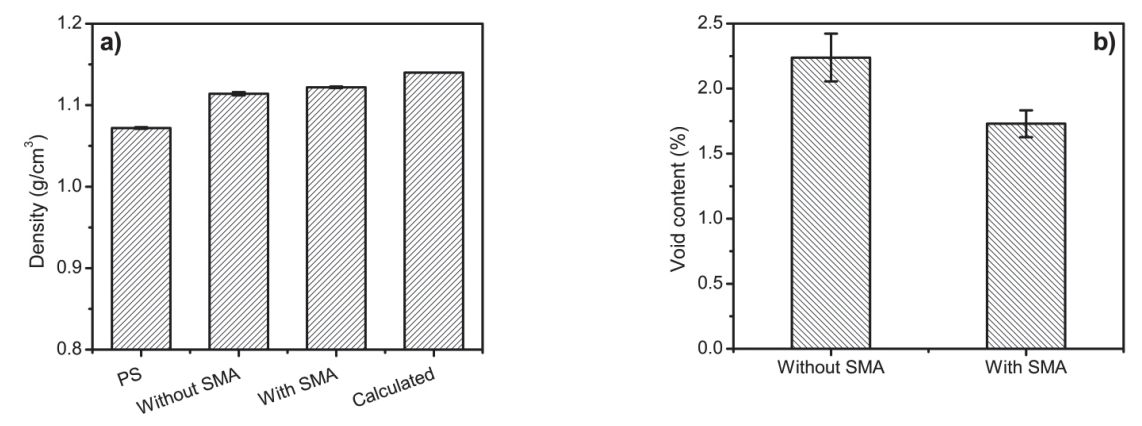

Figure 3. Experimental and calculated density values (a) and void content (b) for matrix and composites with $2 \mathrm{wt} \%$ of SMA 2000.

The void content for WPC with coupling agent was lower than the non-treated composites, as can be seen in Figure 3(b). Composites with good mechanical properties the void content values should be less than 3\% (Padma Priya et al. 2006). WPC with coupling agent had void content value less than $2 \%$, while the non-treated composite value were close to $3 \%$. Thus, the treated composite showed lower void content and better mechanical properties than non-treated one. The decrease in void content for treated composite may indicate the existence of a good bonding between wood flour and matrix in the composite as a result of using SMA 2000. 


\section{Water absorption}

One of the drawbacks related to the use of lignocellulosic filler in composite materials is their high sensitivity to water, which adversely affects their mechanical properties as well as their long term durability in outdoor applications (Naghmouchi et al. 2015). Table 2 shows the water absorption behavior for composites with and without $2 \mathrm{wt} \%$ of SMA 2000. The water absorption for polystyrene was negligible during the time test, and the results were not shown.

The composites treated with SMA 2000 presented higher water absorption values when compared with composites without coupling agent. The addition of SMA 2000 introduces higher quantities of maleic anhydride groups into the composite. These maleic anhydride groups are hydrophilic and may promote an increasing in water absorption for treated composites.

Table 2. Water absorption values for composites with and without coupling agent.

\begin{tabular}{|c|ccc|}
\hline Samples & \multicolumn{3}{|c|}{ Water absorption } \\
\cline { 2 - 4 } & $\mathbf{2 ~ h}$ & $\mathbf{2 4} \mathbf{~ h}$ & $\mathbf{4 8 ~ h}$ \\
& $\mathbf{( \% )}$ & $\mathbf{( \% )}$ & $\mathbf{( \% )}$ \\
\hline Without SMA 2000 & $0,138 \pm 0,015$ & $0,402 \pm 0,001$ & $0,519 \pm 0,055$ \\
With SMA 2000 & $0,174 \pm 0,014$ & $0,467 \pm 0,009$ & $0,662 \pm 0,027$ \\
\hline
\end{tabular}

\section{Morphology characteristics}

The distribution and compatibility between the fiber and the polymer matrix could be observed in SEM study. The SEM micrographs of composites without and with $2 \mathrm{wt} \%$ of coupling agent are shown in Figure 4(a) and (b), respectively. In Figure 4(a), examination of the cryo fracture surface of composite without coupling agent indicated the presence some voids where the fibres have been pulledout and bigger gaps between the wood flour and matrix, which is evidence of weak interfacial adhesion at the interface (Poletto et al. 2011, George et al. 2013). The SEM micrograph of treated composite was presented in Figure 4(b). This SEM micrograph shows the strong bonding and reduced of pulledout traces. This result demonstrated that addition of $2 \mathrm{wt} \%$ of SMA 2000 provides strong interfacial adhesion and good wetting, as evidenced by the almost complete absence of voids in polymer matrix and gaps between the fibre and matrix (Kim et al. 2007, Csikós et al. 2015).
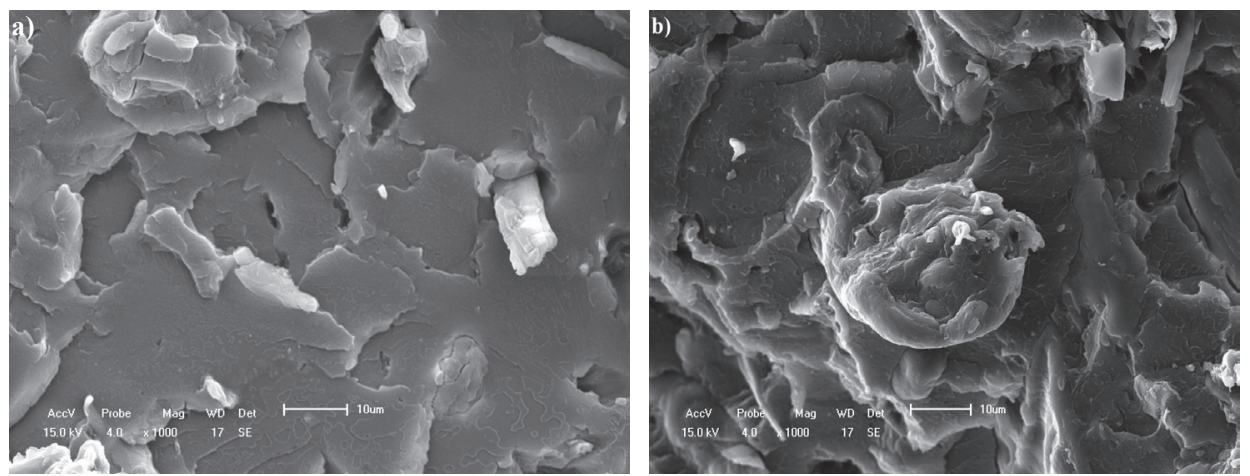

Figure 4. SEM micrographs with magnification of 1000x for (a)composite fracture surfaces without coupling agent and (b) composite fracture surfaces with coupling agent. 


\section{CONCLUSIONS}

The improvement in composite mechanical properties using SMA as coupling agent was strongly dependent on the amount of maleic anhydride into the oligomer and the molecular weight of SMA. Low molecular weight gives sufficient fluidity for SMA in the molten state and thus supports the migration towards the fibre surface improving the adhesion between matrix and wood flour. The highest amount of maleic anhydride groups offers sufficient interactions between SMA and wood flour. The flexural and impact strengths of SMA-treated composites were increased compared to those of SMA non-treated composites. Satisfactory results in mechanical properties mainly in flexural strength were obtained with $2 \%$ in weight of SMA 2000 . The density are almost the same for composites without and with coupling agent, however the void content was reduced in treated composites. Composites treated with SMA 2000 presented higher water absorption that untreated ones, probably because SMA 2000 introduces higher quantities of hydrophilic maleic anhydride groups into the composite. The SEM micrographs confirm better adhesion between wood flour and polystyrene matrix when coupling agent was used.

\section{ACKNOWLEDGEMENTS}

The authors thank Associação de Recicladores Serrano, Madarco Company and Sartomer Company for supplying materials.

\section{REFERENCES}

Adhikary, K.B.; Pang, S.; Staiger, M.P. 2008. Dimensional stability and mechanical behavior of wood-plastic composites based on recycled and virgin high-density polyethylene (HDPE). Composites Part B 39: 807-815.

Bledzki, A.K.; Letman, M., Viksne, A.; Rence, L. 2005. A comparison of compounding processes and wood type for wood fibre-PP composites. Composite Part A36: 789-797.

Bledzki, A.K.; Mamun, A.A.; Volk, J. 2010. Barley husk and coconut shell reinforced polypropylene composites: the effect of fibre physical, chemical and surface properties. Composite Science and Technology 70: 840-846.

Borja, Y.; Rieb, G.; Lederer, K. 2006. Synthesis and characterization of polypropylene reinforced with cellulose I and II fibers. Journal of Applied Polymer Science 101: 364-369.

Csikós, A.; Faludi, G.; Domján, A.; Renner, K.; Móczó, J.; Pukánszky, B. 2015. Modification of interfacial adhesion with a functionalized polymer in PLA/wood composites. European Polymer Journal 68: 592-600.

Cui, Y.; Lee, S.; Noruziaan, B.; Cheung, M.; Tao, J. 2008. Fabrication and interfacial modification of wood/recycled plastic composite materials. Composites Part A 39: 655-661. 
Devaux, E.; Pak, S.H.; Cazé, C. 2002. Effects of the structure os styrene-co-maleic anhydride oligomers on the interfacial properties in a glass fibre reinforced polystyrene composite material. Polymer Testing 21: 773-779.

El-Sabbagh, A. 2014. Effect of coupling agent on natural fibre/polypropylene composites on mechanical and thermal behaviour. Composites Part B 57: 126-135.

Gallagher, L.W.; McDonald A.G. 2013. The effect of micron sized fibers in wood plastic composites. Maderas. Ciencia y tecnología 15: 357-374.

George, G.; Joseph, K.; Nagarajan, E.R.; Tomlal Jose, E.; Skrifvars, M. 2013. Thermal, calorimetric and crystallization behaviour of polypropylene/jute yarn bio-composites fabricated by commingling technique. Composites Part A 48: 110-120.

Khonsari, A.; Taghiyari, H.R.; Karimi, A.; Tajvidi, M. 2015. Study on the effect of wood flour geometry on physical and mechanical properties of wood-plastic composites. Maderas. Ciencia y tecnología 17: 545-558.

Kim, H-S.; Lee, B-H.; Choi, S-W.; Kim, S.; Kim, H-J. 2007. The effect of types of maleic anhydride-grafted polypropylene (MAPP) on the interfacial adhesion properties of bio-flour-filled polypropylene composites. Composites Part A 38: 1473-1482.

Nafchi, H.R.; Abdouss, M.; Najaf, S.K.; Gargari, R.M.; Mazhar, M. 2015. Effects of nanoclay particles and oxidized polypropylene polymers on improvement of the termal properties of wood plastic composite. Maderas. Ciencia y tecnología 17: 45-54.

Naghmouci, I.; Espinach, F.X.; Mutjé, P.; Boufi, S. 2015. Polypropylene composites based on lignocellulosic fillers: how the filler morphology affects the composite properties. Materials and Design 65: 454-461.

Nygård, P.; Tanem, B.S.; Karlsen, T.; Brachet, P.; Leinsvang, B. 2008. Extrusion-based wood fibre-PP composites: wood powder and pelletized wood fibre - a comparative study. Composite Science and Technology 68: 3418-3424.

Ornaghi Jr., H.L.; Poletto, M.; Zattera, A.J.; Amico, S.C. 2014. Correlation of the thermal stability and the decomposition kinetics of six different vegetal fibers. Cellulose 21: 177-188.

Padma Priya S.; Ramakrishna, H.V.; Rai, S.K. 2006. Density, void content, weight reduction and chemical resistance studies on waste silk fabric reinforced acrylonitrile-butadiene-styrene-toughened epoxy composites. Journal of Reinforced Plastics and Composites 25: 339-345.

Poletto, M.; Dettenborn, J.; Zeni, M.; Zattera, A.J. 2011. Characterization of composites based on expanded polystyrene wastes and wood flour. Waste Management 31: 779-784.

Poletto, M.; Zeni, M.; Zattera, A.J. 2012. Effects of wood flour addition and coupling agent content on mechanical properties of recycled polystyrene/wood flour composites. Journal of Thermoplastic Composite Materials 25: 821-833.

Poletto, M.; Zattera, A.J.; Santana, R.M.C. 2014. Effect of natural oils on the stability and degradation kinetics of recycled polypropylene wood flour composites. Polymer Composites 10: 19351942.

Poletto, M.; Zattera, A.J. 2015. Mechanical and dynamic mechanical properties of polystyrene composites reinforced with cellulose fibers: coupling agent effect. Journal of Thermoplastic Composite Materials DOI: 10.1177/0892705715619967. 
Sliwa, F.; EI Bounia, N.; Charrier F.; Marin, G.; Malet, F. 2012. Mechanical and interfacial properties of wood and bio-based thermoplastic composites. Composite Science and Technology 72: $1733-1740$.

Sommerhuber, P.F.; Wang, T.; Krause, A. 2016. Wood-plastic composites as potential applications of recycled plastics of electronic waste and recycled particleboard. Journal of Cleaner Production 121: 176-185.

Takagi, H. Asano, A. 2008. Effects of processing conditions on flexural properties of cellulose nanofibers reinforced "green" composites. Composites Part A 39: 685-689. 